\title{
Zinc-finger transcriptional factor Sall1 induces angiogenesis by activation of the gene for VEGF-A
}

\author{
Chii Yamamoto ${ }^{1}$, Noboru Fukuda $^{1}$, Taro Matsumoto $^{2}$, Terumi Higuchi ${ }^{3}$, Takahiro Ueno ${ }^{3}$ \\ and Koichi Matsumoto ${ }^{3}$
}

Zinc-finger transcriptional factor Sall1 modulates gene expression and regulates organogenesis, including kidney development. Angiogenesis induced by vascular endothelial growth factor (VEGF) is also required for organogenesis. We investigated whether Sall1 induces angiogenesis through VEGF gene activation. Sall1 gene transfer induced marked neovascularization in rat cornea and in mouse embryoid bodies (EBs). The neovascularization in EBs was abolished by co-administration of anti-VEGF antibody. Sall1 gene transfer in Swiss 3T3 cells significantly increased the expression of VEGF-A mRNA but did not markedly increase the expression of fibroblast growth factor-2, epidermal growth factor, hepatocyte growth factor and ETS-1 mRNA. Sall1 gene transfer significantly increased VEGF-A protein levels in conditioned medium from cultured fibroblasts. Sall1 gene transfer significantly increased VEGF-A promoter activity in HEK293T cells as compared with cells transfected with mock vector or truncated Sall1. These results suggest that Sall1 induces angiogenesis by stimulating VEGF-A promoter activity. Hypertension Research (2010) 33, 143-148; doi:10.1038/hr.2009.195; published online 27 November 2009

Keywords: angiogenesis; embryoid body; Sall1; VEGF; zinc-finger protein

\section{INTRODUCTION}

Angiogenesis, the formation of capillaries from preexisting vessels, has a central role in a variety of physiological and pathological conditions. ${ }^{1,2}$ A growing number of diseases, such as cancer, chronic inflammation and diabetic retinopathy, are characterized by excess angiogenesis. Progression of these diseases may depend on the attraction of blood vessels to oxygenate and nurture growing tissue. In addition, angiogenesis has an important role in the formation of collateral arteries in peripheral and myocardial ischemia. The promotion of angiogenesis in ischemic tissue in cardiovascular diseases is at present the subject of intensive research. ${ }^{3}$

Angiogenesis can be considered as a series of temporally regulated events involving proteolytic digestion of the extracellular matrix, proliferation and migration of endothelial cells, formation of functional capillaries and remodeling of the vascular bed through apoptosis. A complex network of growth factors and cytokines regulates angiogenesis. ${ }^{4}$ Destabilization of the existing basement membrane and degradation of extracellular matrix are mediated by angiopoietin-2, an inhibitor of Tie-2 signaling. ${ }^{5}$ Vascular endothelial growth factor-A (VEGF-A) and fibroblast growth factor (FGF) stimulate endothelial cell proliferation and migration, which is followed by differentiation and the formation of a lumen. Platelet-derived growth factor recruits the supporting cells, such as pericytes and smooth muscle cells, ${ }^{6}$ whereas signaling by transforming growth factor- $\beta 1$ and angiopoietin-1 stabilizes the interaction between endothelial and smooth muscle cells. ${ }^{7}$ Expression of these peptides is spatially and temporally regulated during angiogenesis by many transcriptional factors.

Sall1 is a multi-zinc finger transcriptional factor that has been shown to regulate the development of several organs. ${ }^{8-10}$ Recently, engineered zinc-finger transcription factors have been reported to promote therapeutic angiogenesis by induction of the VEGF-A gene. ${ }^{11,12}$ Synthetic zinc-finger proteins activate expression of the VEGF-A gene at a level exceeding that induced by hypoxic stress. ${ }^{13}$

In this study, to investigate whether Sall1 promotes angiogenesis, we examined the effects of Sall gene transfer on neovascularization and on the expression of angiogenic growth factors.

\section{METHODS}

Animals

Our investigation conformed to the Guide for the Care and Use of Laboratory Animals published by the US National Institutes of Health (NIH Publication No. 85-23, revised 1996). The 12-week-old male Sprague-Dawley rats were purchased from CLEA Japan (Tokyo, Japan).

\section{Vectors}

The mammalian expression vector pCMV-Myc/Sall1 (a kind gift from Ryuichi Nishinakamura; Kumamoto University, Kumamoto, Japan) was constructed by inserting complete coding mouse Sall1 cDNA (4126 bp) between the SalI-NotI restriction enzyme site of the multiple cloning site in pCMV-myc (Clontech, Palo Alto, CA, USA). This construct is a mammalian expression vector that

${ }^{1}$ Advanced Research Institute of Science and Humanities, Nihon University, Tokyo, Japan; ${ }^{2}$ Division of Cell Regeneration and Transplantation, Department of Advanced Medicine, Nihon University School of Medicine, Tokyo, Japan and ${ }^{3}$ Division of Nephrology, Hypertension and Endocrinology, Department of Medicine, Nihon University School of Medicine, Tokyo, Japan

Correspondence: Dr N Fukuda, Advanced Research Institute of Science and Humanities, Nihon University, Ooyaguchi-kami 30-1, Itabashi-ku, Tokyo 173-8610, Japan. E-mail: fukudan@med.nihon-u.ac.jp

Received 28 August 2009; accepted 25 October 2009; published online 27 November 2009 
expresses an N-terminal c-Myc epitope tag. A truncated pCMV-Myc/Salll was constructed by amplifying the fragments digested with NotI and XheI. This construct was subcloned with a DNA fragment of the Sall1 gene lacking c-terminal zinc-finger domains. pCMV-Myc/GFP vector (a kind gift from Ryuichi Nishinakamura) was used for control transfections and to evaluate transfection efficiency. The VEGF-A promoter (VEGF-A-Luc) reporter construct has been described previously and was a kind gift from Dr Peter Carmeliet (Vesalius Research Centre, Leuven, Belgium).

\section{Cell culture}

The mouse embryonic stem cell line R1, derived from the SvJ129 strain, was a kind gift from Dr A Nagy (Samuel Lunenfeld Research Institute, Mount Sinai Hospital, Toronto, ON, Canada). Embryonic stem cells were cultured in a medium composed of Dulbecco's modified Eagle's medium (DMEM, Invitrogen, Carlsbad, CA, USA) supplemented with 15\% heat-inactivated fetal bovine serum (FBS), $25 \mathrm{mmoll}^{-1} \mathrm{HEPES}, 1.2 \mathrm{mmoll}^{-1} \mathrm{Na}$-pyruvate (Invitrogen), $19 \mu \mathrm{moll}^{-1}$ monothioglycerol (Sigma, St Louis, MO, USA) and $1000 \mathrm{U} \mathrm{ml}^{-1}$ recombinant leukemia inhibitory factor (LIF; Chemicon International, Harrow, UK). Cells were cultured at $37^{\circ} \mathrm{C}$ with $5 \% \mathrm{CO}_{2}$. The medium was changed every day, and splitting was carried out every second or third day. To induce differentiation, LIF was withdrawn from the medium. Swiss 3 T3 cells (a mouse fibroblast cell line) used for transient expression of Sall1 were maintained in DMEM containing $10 \%$ FBS, $100 \mathrm{IU} \mathrm{ml}^{-1}$ of penicillin and $100 \mu \mathrm{g} \mathrm{ml}^{-1}$ of streptomycin (Invitrogen). HEK293T cells used for the luciferase reporter assay were maintained in DMEM containing 10\% FBS.

\section{Rat corneal angiogenesis assay}

The rat corneal assay was carried out as described previously. ${ }^{11}$ Briefly, $1 \mu \mathrm{g}$ of pCMV-Myc/Sall1 or pCMV-Myc/GFP and HVJ-envelope vector (Ishihara Sangyo Kaisha, Osaka, Japan) was mixed with $5 \mu$ l of a solution of ethylene vinyl acetate copolymer (Mitsui Dupon Chemical, Tokyo, Japan) in dichloromethane and frozen. The frozen pellet was inserted surgically into pockets created in corneal stroma and placed $3 \mathrm{~mm}$ from the corneoscleral limbus in 12-week-old Sprague-Dawley rats. Seven days after the pellet was implanted, $20 \mu \mathrm{l}$ of $10 \%$ formalin solution and $20 \mu \mathrm{l}$ of Indian ink were infused into both carotid arteries in rats under pentobarbital anesthesia. The eyes were removed and capillary formation was examined with a biomicroscope (Keyence, Osaka, Japan). Vessel length was measured and vessel area was calculated as described. ${ }^{9}$

\section{Angiogenesis assay in embryoid bodies (EBs)}

Mouse ES cells $\left(6 \times 10^{5}\right)$ were transfected with pCMV-Myc/Sall1 or pCMVMyc/GFP, using the HVJ-envelope Vector kit GenomONE (Ishihara Sangyo Kaisha, Osaka, Japan), according to the manufacturer's instructions. Induction of angiogenesis in mouse EBs was described previously. ${ }^{14}$ Briefly, dissociated ES cells were cultured in hanging drops ( 1200 cells $20 \mu \mathrm{l}^{-1}$ medium without LIF; denoted day 0 ) to induce aggregation. After 4 days, EBs were plated individually in 8-well culture slides (BD Biosciences, San Jose, CA, USA) and incubated with ES medium without LIF. Media were changed every fourth day. EBs transfected with pCMV-Myc/Salll were cultured with $0.05 \mu \mathrm{g} \mathrm{ml}^{-1}$ anti-VEGFA antibody (R\&D Systems, Minneapolis, MN, USA). For positive control, EBs were cultured in the presence of $20 \mathrm{ng} \mathrm{ml}^{-1}$ VEGF-A. On day 8, EBs were fixed for $10 \mathrm{~min}$ in $4 \%$ paraformaldehyde, blocked with blocking buffer containing $10 \%$ goat serum and $1 \%$ bovine serum albumin in phosphate-buffered saline at room temperature for $1 \mathrm{~h}$. Samples were then incubated with rat anti-mouse $\mathrm{CD} 31$ (BD Biosciences) overnight at $4{ }^{\circ} \mathrm{C}$. After washing with phosphatebuffered saline, EBs were incubated for $1 \mathrm{~h}$ at room temperature with secondary antibody Alexa 594 goat anti-rat IgG in blocking buffer. Coverslips were mounted using Fluoromount-G (Southern Biotechnology, Birmingham, AL, USA) and examined with an immunofluorescence microscope (Nikon Eclipse TE 2000-U, Nikon, Tokyo, Japan). Quantification of CD31 staining was carried out with Lumina Vision software (version 2.0, Mitani, Tokyo, Japan).

\section{Reverse-transcription polymerase chain reaction analysis}

Swiss 3T3 cells were plated at a density of $7.5 \times 10^{4}$ cells per well of a 6 -well dish and transfected with pCMV-Myc/Salll or pCMV-Myc/GFP using HVJenvelope Vector kit GenomONE according to the manufacturer's instructions.
Twenty-four hours after transfection, total RNA was extracted from culture cells using Trizol reagent (Invitrogen). Reverse-transcription polymerase chain reaction was carried out as described previously. Briefly, aliquots of RNA $(1 \mu \mathrm{g})$ were reverse-transcribed into single-stranded cDNA using $0.25 \mathrm{U}$ of avian myeloblastoma virus reverse transcriptase (Takara Biochemicals, Osaka, Japan) in $10 \mathrm{mmoll}^{-1}$ Tris- $\mathrm{HCl}$ ( $\mathrm{pH} 8.3$ ), $5 \mathrm{mmoll}^{-1} \mathrm{MgCl}_{2}, 50 \mathrm{mmoll}^{-1} \mathrm{KCl}$, $1 \mathrm{mmoll}^{-1}$ deoxy-NTPs and $2.5 \mathrm{moll}^{-1}$ random hexamer. A total of $5 \mu \mathrm{l}$ of the diluted cDNA product was mixed with $10 \mathrm{~mm}$ Tris- $\mathrm{HCl}(\mathrm{pH} 8.3), 50 \mathrm{mmoll}^{-1}$ $\mathrm{KCl}, 4 \mathrm{mmoll}^{-1} \mathrm{MgCl}_{2}$ and $0.025 \mathrm{U}$ of Taq DNA polymerase (Takara Biochemicals, Osaka, Japan), as well as $0.2 \mathrm{M}$ each of the upstream sense primer and downstream antisense primer. The primers used for Sall1, VEGF-A, FGF-2, hepatocyte growth factor, Ets-1 and glyceraldehyde-3-phosphate dehydrogenase (GAPDH) mRNA are shown in Table 1. To confirm that no genomic DNA was coamplified, identical reverse-transcription polymerase chain reaction amplification reactions were performed in the absence of reverse transcriptase. PCR was performed with a DNA Thermal Cycler (Perkin Elmer Cetus, Norwalk, CT, USA). To perform semiquantitative analysis of the target mRNAs, the kinetics of the PCR amplification reaction for each target mRNA were determined according to previously established procedures. Following initial denaturation at $96^{\circ} \mathrm{C}$ for $5 \mathrm{~min}$, amplification was performed as follows: Sall1: 25 cycles of $94^{\circ} \mathrm{C}$ for $1 \mathrm{~min}, 62^{\circ} \mathrm{C}$ for $1 \mathrm{~min}$, and $72{ }^{\circ} \mathrm{C}$ for $1 \mathrm{~min}$; VEGF-A: 30 cycles of $94^{\circ} \mathrm{C}$ for $30 \mathrm{~s}, 60^{\circ} \mathrm{C}$ for $1 \mathrm{~min}$, and $72^{\circ} \mathrm{C}$ for $1 \mathrm{~min}$; FGF-2: 30 cycles of $94^{\circ} \mathrm{C}$ for $30 \mathrm{~s}, 60^{\circ} \mathrm{C}$ for $1 \mathrm{~min}$, EGF: 30 cycles of $94^{\circ} \mathrm{C}$ for $30 \mathrm{~s}, 60^{\circ} \mathrm{C}$ for $1 \mathrm{~min}$, and $72^{\circ} \mathrm{C}$ for $1 \mathrm{~min}$; Ets-1: 30 cycles of $94^{\circ} \mathrm{C}$ for $30 \mathrm{~s}, 60^{\circ} \mathrm{C}$ for $1 \mathrm{~min}$, and $72^{\circ} \mathrm{C}$ for $1 \mathrm{~min}$; hepatocyte growth factor: 30 cycles of $94^{\circ} \mathrm{C}$ for $30 \mathrm{~s}, 60^{\circ} \mathrm{C}$ for $1 \mathrm{~min}$ and $72{ }^{\circ} \mathrm{C}$ for $1 \mathrm{~min}$, with final extension for $10 \mathrm{~min}$ at $72^{\circ} \mathrm{C}$. PCR for glyceraldehyde-3-phosphate dehydrogenase was also carried out with each reaction as an internal control. The PCR products were electrophoresed on $1.5 \%$ agarose gel.

\section{Measurement of VEGF-A protein level}

Swiss 3T3 cells were transfected with pCMV-Myc/Sall1 or pCMV-Myc/GFP by $\mathrm{HVJ}$-envelope vector and cultured for $24 \mathrm{~h}$ in a $\mathrm{CO}_{2}$ incubator. VEGF-A protein levels in the media were measured by enzyme-linked immunoabsorbent assay (ELISA, TECHNE, Minneapolis, MN, USA).

\section{Luciferase reporter assay}

HEK293T cells were seeded onto 24-well plates and grown in DMEM with 20\% FBS. At $70-90 \%$ confluence, the cells were co-transfected with $1 \mathrm{mg}$ pCMVMyc/Sall1, $0.1 \mu \mathrm{g}$ VEGF-A-Luc promoter plasmid and $0.01 \mu \mathrm{g}$ phRG-TK vector (containing the cDNA encoding Renilla luciferase, Promega, Madison, WI, USA) by using Lipofectamine2000 transfection reagent (Invitrogen). As control, cells were transfected with $1 \mu \mathrm{g}$ of pCMV-Myc/GFP or $1 \mu \mathrm{g}$ of truncated

\section{Table 1 PCR primers and product sizes}

\begin{tabular}{lllc}
\hline mRNA & Primers & Sequence & Product size (bp) \\
\hline Sall1 & Sense & 5'-CCCCATCCCTATTAGCCATT-3' & 198 \\
& Antisense & 5'-AGAGTACTGTTGCCCGCTGT-3' & \\
VEGF-A & Sense & 5'-ACTGGACCCTGGCTTTACTG-3' & 256 \\
& Antisense & 5'-ACGCACTCCAGGGCTTCATC-3' & \\
FGF-2 & Sense & 5'-AAGCGGCTCTACTGCAAG-3' & \multirow{2}{*}{372} \\
& Antisense & 5'-AGCCAGACATTGGAAGAAACA-3' & \\
EGF & Sense & 5'-GAGAGGTGCAGAAGGACCTG-3' & 271 \\
& Antisense & 5'-CACCAATTGCTGGTGATTTG-3' & \\
HGF & Sense & 5'-CAGTCTGCTCGAACTGCAAG-3' & 269 \\
& Antisense & 5'-AACGTAAAGCCCCTGTTCCT-3' & \\
Ets-1 & Sense & 5'-GATGTCCCAAGCCTTGAAAA-3' & 133 \\
& Antisense & 5'-GAACTCATTCACAGCCCACA-3' & \\
GAPDH & Sense & 5'-GGGTGTGACCACGAGAAAT-3' & 167 \\
& Antisense & 5'-CCACAGTCTTCTGAGTGGCA-3' &
\end{tabular}

Abbreviations: EGF, epidermal growth factor; FGF-2, fibroblast growth factor-2; GAPDH, glyceraldehyde-3-phosphate dehydrogenase; HGF, hepatocyte growth factor; VEGF-A, vascular endothelial growth factor-A. 
pCMV-Myc/Sall1. Cells were incubated for an additional $24 \mathrm{~h}$ and scraped into $100 \mu \mathrm{l}$ of lysis buffer. Luciferase activity was measured with a dual-luciferase reporter assay system (Promega) and a TD-20/20 luminometer (Tumer Designs, Sunnyvale, CA, USA).

\section{Statistical analysis}

Statistical analysis was performed by the unpaired Student's $t$ - and Welch's $t$-test. Data were expressed as the mean \pm s.e.m. Differences were considered significant at the level of $P<0.05$.

\section{RESULTS}

\section{Sall1-induced neovascularization in rat cornea}

We first examined whether Sall1 gene transfer promotes angiogenesis in vivo. For the in vivo angiogenesis assay, we employed the rat cornea micropocket assay. This assay allows the neovascularized area to be inspected directly; the vascular pattern can be clearly distinguished from newly formed vessels. When Sall1 expression vector (pCMVmyc/Sall1) was implanted in corneal stroma with an HVJ-envelope, obvious capillary formation extended toward the implanted pellet from the limbus across the rat cornea within 7 days after the implantation (Figure 1a). In contrast, transfection of control vector (pCMV-myc/GFP) did not induce neovascularization, although GFP expression was clearly detected at the corneal pocket. Quantitative analysis of neovascularization revealed that Sall1 gene transfer significantly $(P<0.05)$ increased the neovascularized area as compared with the control gene transfer (Figure 1b). These results indicate that Sall gene transfer induces angiogenesis in vivo.

\section{Sall1-induced neovascularization in mouse EBs}

Murine embryonic stem cells were aggregated in hanging drops to create EBs. The development of vessel-like structures in EBs has been documented; the spatial and temporal expression patterns of endothelial cell markers very closely mimic those observed in vivo. We next examined the effect of Sall1 gene transfer on vascular development in the mouse EB angiogenesis model. When EBs were cultured in the presence of $20 \mathrm{ng} \mathrm{ml}^{-1}$ VEGF-A and stained immunohistochemically
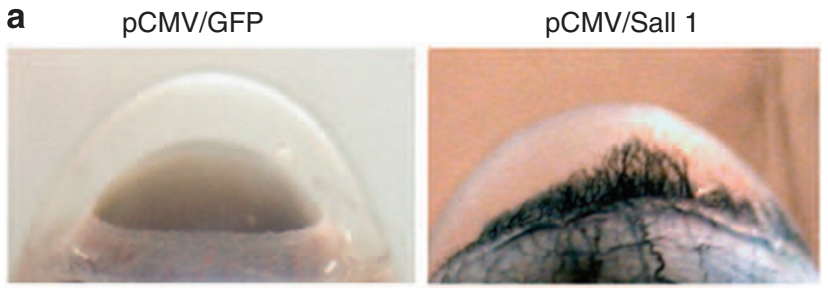

b

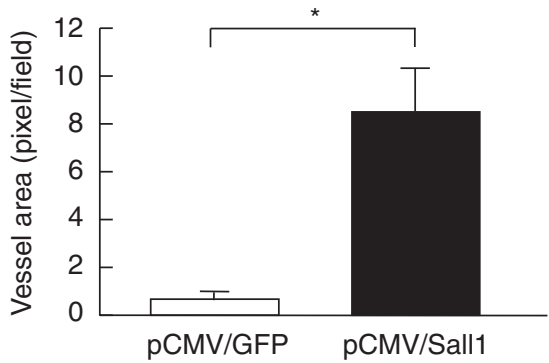

Figure 1 Angiogenesis in rat cornea after Sall1 gene transfer. (a) A volume of $1 \mu \mathrm{g}$ of pCMV-Myc/GFP (pCMV/GFP) or $1 \mu \mathrm{g}$ of pCMV-Myc/Sall1 (pCMV/ Sall1) was inserted in corneas of Sprague-Dawley rats. Seven days after implantation the eyes were removed and capillary formation was examined. (b) The area of abundant capillary formation was evaluated by densitometric analysis. Data are the mean \pm s.e.m. $(n=3)$. ${ }^{*} P<0.05$. with an antibody against CD31, a marker for endothelial cells, CD31-positive fine capillary-like structures were induced in the periphery of EBs at day 8. Sall1 gene transfer led to the induction of capillary-like structures in EBs in the absence of VEGF-A. The morphology of the capillary-like structures in Sall1-transfected EBs included a compact plexus of capillaries in the periphery, which was similar to that in VEGF-A-treated EBs. In contrast, gene transfer of mock vector induced less angiogenesis. Co-administration of antiVEGF antibody abolished the induction of capillary-like structures by Sall1 gene transfer (Figure 2a). Quantification of vessel length revealed that vessels in Sall1-transfected EBs are significantly $(P<0.05)$ longer than those in mock-transfected EBs. Anti-VEGF antibody significantly $(P<0.05)$ reduced vessel length in Sall1-transfected EBs (Figure 2b). These results suggest that Sall1 has an important role in vascular development through VEGF-mediated angiogenesis.

Sall1 increased VEGF expression and stimulated VEGF-A promoter activity

To further assess pro-angiogenic mechanisms induced by Sall1 gene transfer, mRNA expression of angiogenic factors was measured by reverse-transcription polymerase chain reaction analysis in Sall1transfected Swiss 3T3 fibroblasts. Sall1 gene transfer considerably increased the expression of VEGF-A mRNA, but did not considerably increase expression of FGF-2, EGF, hepatocyte growth factor and Ets-1 mRNAs (Figure 3). The abundance of VEGF-A mRNA was significantly $(P<0.05)$ greater in the cells expressing Sall1, as compared with mock-transfected cells or HVJ-envelope-treated cells (Figure 4a). Protein levels of VEGF-A were also significantly $(P<0.05)$ greater in cells expressing Sall1 compared with mock-transfected cells or HVJenvelope-treated cells (Figure $4 \mathrm{~b}$ ). These results indicate that Sall1 gene transfer stimulates VEGF-A expression in fibroblasts.

To determine whether the effect of Sall1 on VEGF-A gene and protein expression was mediated at a transcriptional level, HEK293T cells were transiently co-transfected with VEGF-A promoter-luciferase constructs and Sall1 expression vector. Luciferase activity of VEGF-A was measured $24 \mathrm{~h}$ after transfection. VEGF-A promoter activity in Sall1-transfected cells was significantly $(P<0.05)$ higher than that in cells transfected with mock vector or truncated Sall1 gene lacking the c-terminal zinc-finger domains (Figure 5). These findings indicate that Sall1 promotes VEGF-A promoter activity through interaction with zinc-finger domains of Sall1.

\section{DISCUSSION}

In this study, we found that the gene transfer of a zinc-finger transcriptional factor Sall1-induced marked capillary neovascularization in rat cornea and in mouse EBs. Sall1 gene transfer increased the expression of VEGF-A mRNA and protein and increased VEGF-A promoter activity. Sall1 gene transfer did not increase the expression of other angiogenic mRNA factors such as FGF-2, EGF, hepatocyte growth factor and Ets-1. These results suggest that Sall1 is involved in angiogenesis through VEGF-A promoter activation.

Zinc-finger protein acts as a transcriptional factor to control many gene functions. Recently, engineered polydactyl zinc-finger transcription factors have been designed and artificially synthesized for the transcriptional regulation of target genes. ${ }^{15}$ Liu et al. ${ }^{13}$ reported that zinc-finger proteins can bind with high affinity to diverse DNA sequences present within the VEGF-A locus capable of activating the expression of the endogenous chromosomal VEGF-A gene. It should be noted that DNase I-accessible regions are characterized with respect to their DNA-binding properties and ability to activate VEGF-A expression. Furthermore, VEGF-A gene expression is regulated by 
a

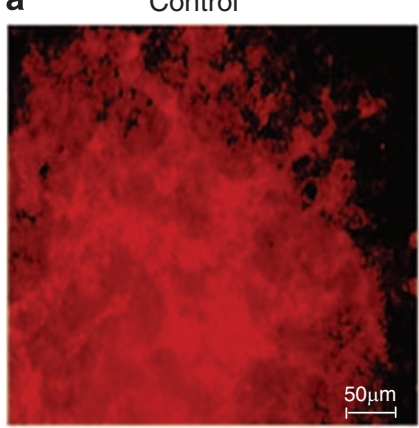

$50 \mu \mathrm{m}$
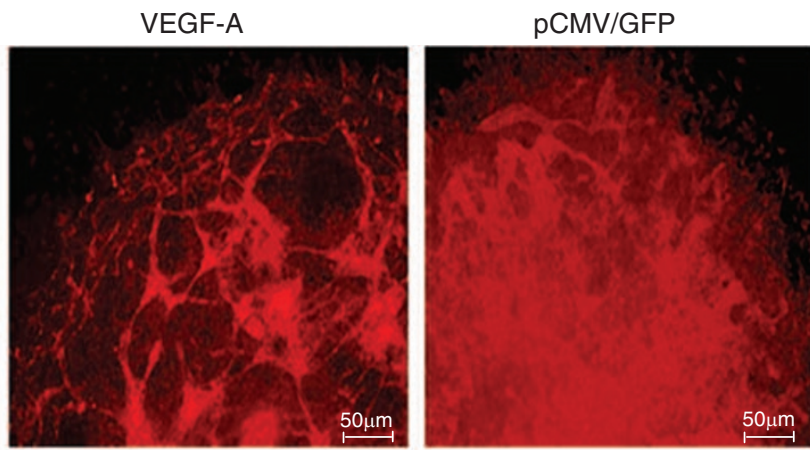

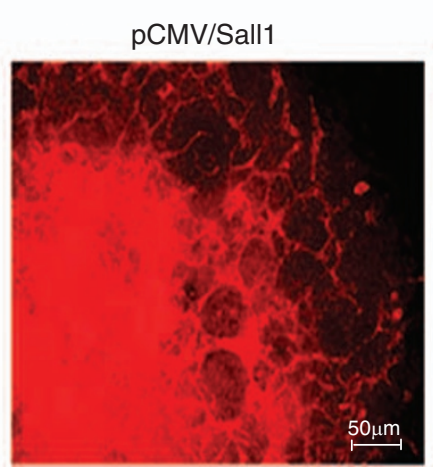

pCMV/Sall1+

Anti-VEGFAb

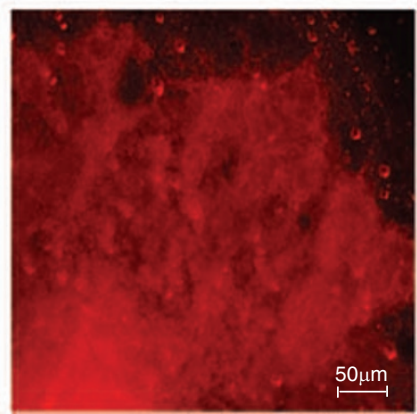

b

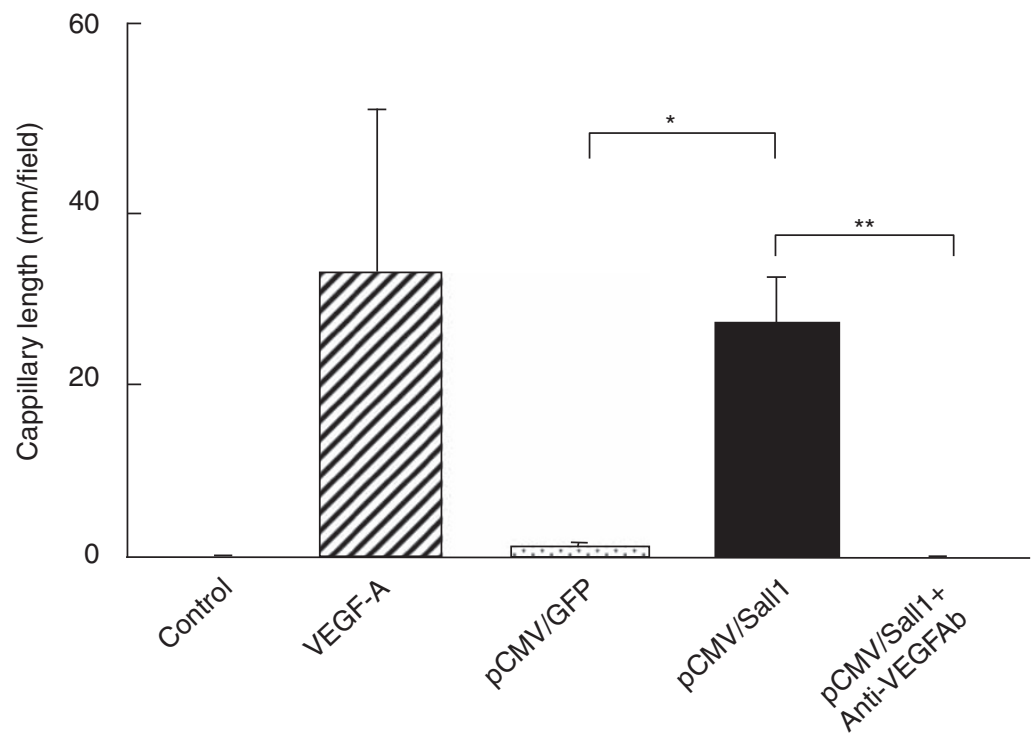

Figure 2 Angiogenesis in embryoid bodies (EBs) after Sall1 gene transfer. Mouse EBs were transfected without plasmid (control) or with pCMV-Myc/GFP (pCMV/GFP) or pCMV-Myc/Sall1 (pCMV/Sall1), or treated with recombinant vascular endothelial growth factor (VEGF-A) or anti-VEGF antibody (anti-VEGF Ab). (a) On day 8, EBs were fixed and stained with CD31 antibody. (b) Quantification analysis of vessel length from EBs with Lumina Vision software. Data are the mean \pm s.e.m. $(n=4) .{ }^{*} P<0.05,{ }^{*} P<0.01$.

a variety of stimuli. Hypoxia is a key regulator of VEGF expression via the hypoxia-inducible factor-1/von Hippel-Lindau tumor suppression gene pathway. Apart from hypoxia, growth factors and cytokines including platelet-derived growth factor, EGF, FGF, tumor necrosis factor- $\alpha$, transforming growth factor- $\alpha$ and transforming growth factor- $\beta$, keratinocyte growth factor, insulin-like growth factor-1, interleukin- $1 \beta$ and interleukin- 6 upregulate transcription of VEGF-A mRNA. Several proangiogenic oncogenes and transcription factors, including Src, c-Myc, Fos, and Bcl-2 also upregulate VEGF mRNA expression. VEGF-A promoters from the different species exhibit homology including consensus sites for specificity protein-1/specificity protein-3, activating protein-2, early gene response protein-1, as well as signal transducers and transcription activators. ${ }^{16}$ It has also been shown that a cryptic promoter is present in a domain originally described as part of the $5^{\prime}$ non-coding region of the VEGF-A mRNA. ${ }^{17}$ In this study, VEGF-A promoter activity in Sall1-transfected cells was significantly higher than that in cells transfected with mock vector or truncated Sall1 gene lacking c-terminal zinc-finger domains. Thus, Sall1 gene transfer induces strong angiogenesis through VEGF-A promoter stimulation by zinc-finger protein activity. 
In humans, mutations in Sall1 cause an autosomal dominant disorder, Townes-Brocks syndrome, resulting in ear, limb, anal, renal and heart anomalies. ${ }^{10}$ Although Sall1 modulates gene expression and regulates organogenesis, the role of Sall1 in vascular development is not clear. Nishinakamura et al. ${ }^{18}$ demonstrated that homozygous Sall1-deficient mice show severe renal dysplasia or complete renal agenesis; however, the mice exhibit normal vascular development. Sall1 is localized to heterochromatin and acts as a transcriptional repressor in mammalian cells. ${ }^{19,20}$ Sall binds to the A/T-rich sequences of major satellites in heterochromatin through its c-terminal zinc-finger domains. ${ }^{21}$ Because small amounts of Sall1 are

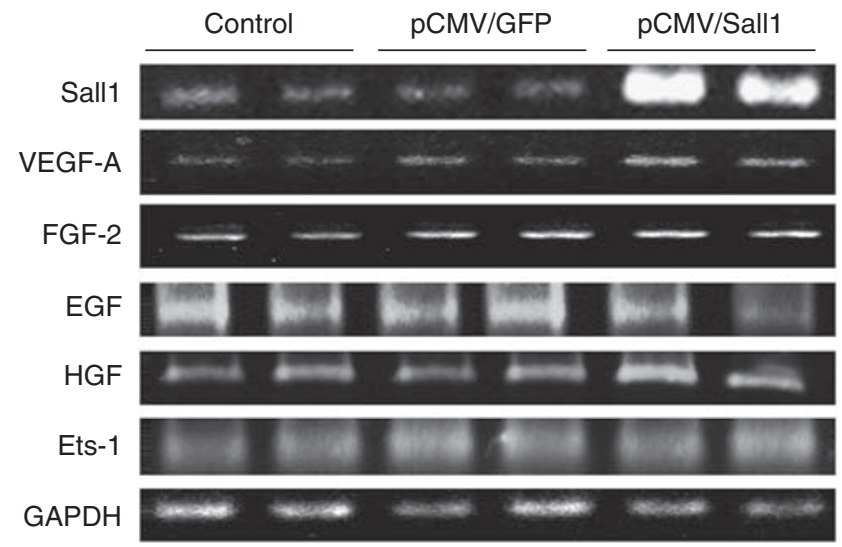

Figure 3 Effects of Sall1 gene transfer on mRNA expression of angiogenic factors in Swiss 3T3 cells. Cells were incubated with HVJ-envelope vector alone (control) and were transfected with pCMV-Myc/GFP (pCMV/GFP) or pCMV-Myc/Sall1 (pCMV/Sall1) by HVJ-envelope. Expression of Sall1, vascular endothelial growth factor (VEGF)-A, fibroblast growth factor (FGF)2, epidermal growth factor (EGF), hepatocyte growth factor (HGF), Ets-1 and glyceraldehyde-3-phosphate dehydrogenase (GAPDH) mRNA was examined by reverse-transcription polymerase chain reaction analysis $24 \mathrm{~h}$ after transfections. expressed in non-heterochromatic regions, it is unlikely that endogenous Sall1 acts as a conventional transcription factor in the body to regulate the expression of genes including VEGF-A. Target inactivation of VEGF-A interferes with angioblast differentiation and consequently with vasculogenesis. The critical need for appropriate levels of VEGF-A expression was demonstrated by the finding that absence of only one of the two alleles led to abnormal vasculature and embryonic lethality. ${ }^{22,23}$ These findings suggest that endogenous Sall1 does not

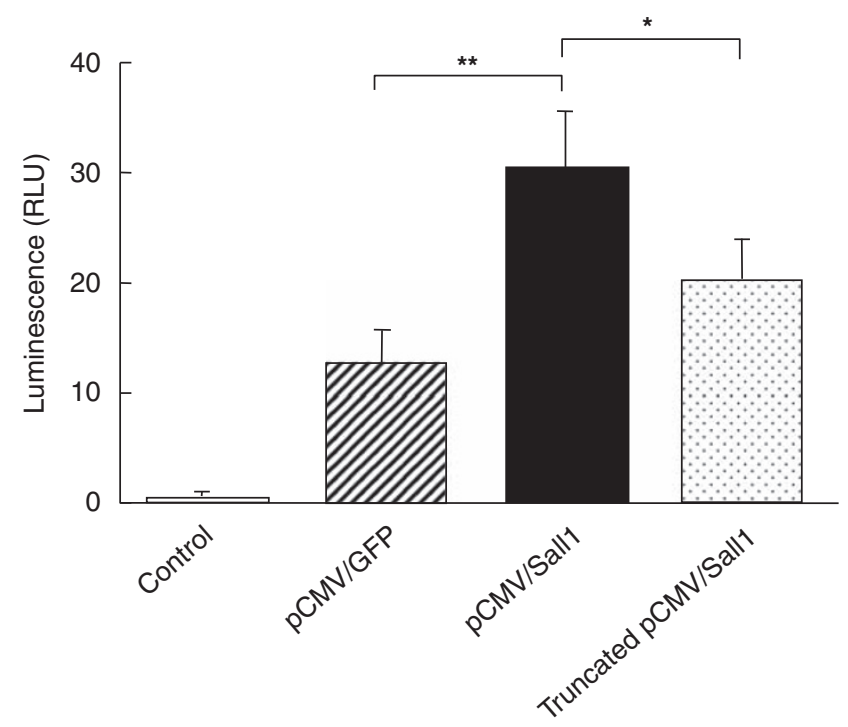

Figure 5 Effects of Sall1 gene transfer on vascular endothelial growth factor (VEGF)-A promoter activity. HEK293T cells transfected with plasmids of VEGF-A-luciferase plasmid and Renilla luciferase reporter plasmid. Cells were co-transfected without (control) and with pCMV-Myc/GFP (pCMV/GFP), truncated pCMV-Myc/Sall1 (Truncated pCMV/Sall1), or pCMV-Myc/Sall1 (pCMV/Sall1). Luciferase activity was measured $24 \mathrm{~h}$ after the transfections. Data are the mean \pm s.e.m. $(n=4) .{ }^{*} P<0.05,{ }^{* *} P<0.01$.
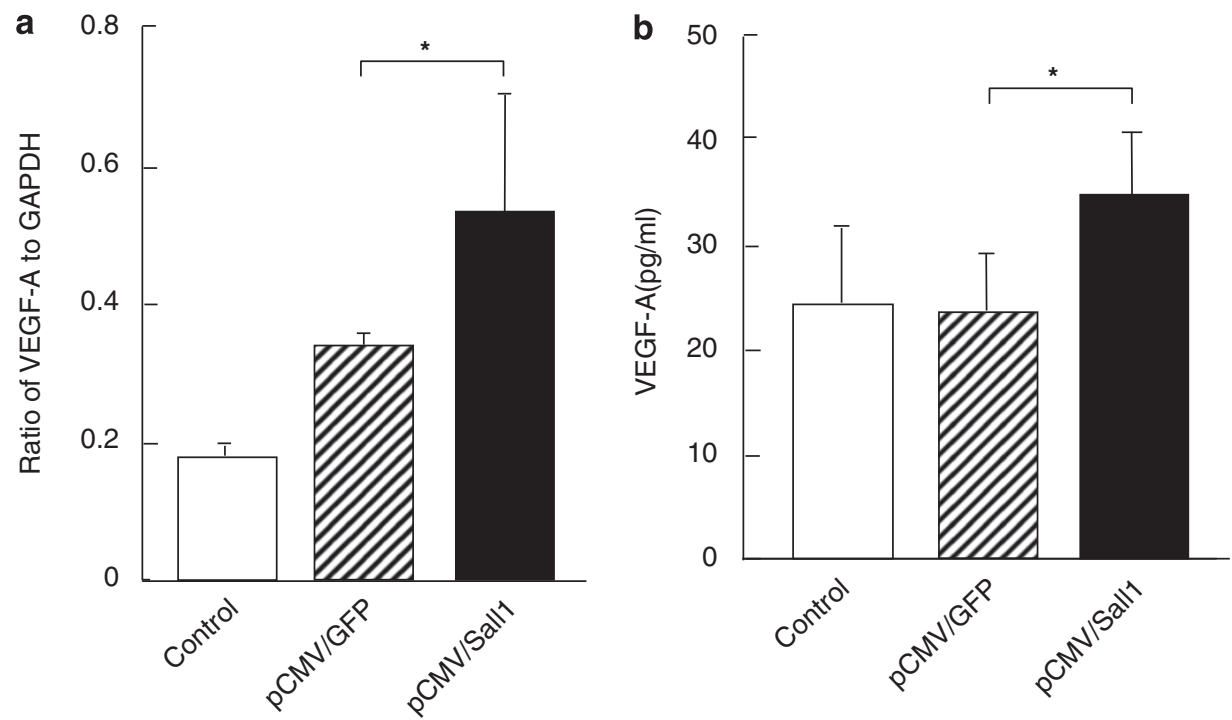

Figure 4 Effects of Sall1 gene transfer on the expression of vascular endothelial growth factor (VEGF)-A mRNA and production of VEGF-A protein. (a) Swiss $3 T 3$ cells were incubated with HVJ-envelope vector alone (control) and were transfected with pCMV-Myc/GFP (pCMV/GFP) or pCMV-Myc/Sall1 (pCMV/Sall1) by HVJ-envelope. Expression of VEGF-A and glyceraldehyde-3-phosphate dehydrogenase (GAPDH) mRNA was examined by reverse-transcription polymerase chain reaction analysis. The ratio of VEGF-A to GAPDH was evaluated by densitometric analysis. Data are mean \pm s.e.m. $(n=4) * P<0.05$. (b) Production of VEGF-A protein was determined by ELISA in conditioned medium from Swiss $3 T 3$ cell cultures $24 \mathrm{~h}$ after transfection. Data are the mean \pm s.e.m. ( $n=4$ ). ${ }^{*} P<0.05$ 
affect VEGF-A expression during embryonic development. Overexpression of exogenous Sall1 may allow Sall1 protein to bind to the promoter region of the VEGF-A gene and stimulate transcription.

Angiogenesis is an essential step in the development of almost all organs, including kidney. Robert et al. ${ }^{24}$ immunoblotted kidneys with antibodies against a VEGF receptor, Flk-1, to identify the origin of cells in the glomerular capillary tufts. The results showed that embryonic kidney cells expressing Flk-1 are angioblasts. Thus, the cells involved in glomerular capillary formation during nephrogenesis are angioblasts that create microvessels and glomeruli by angiogenesis. There have been no reports that Sall1 induces vasculogenesis during the nephrogenic process. VEGF is an endothelial cell-specific mitogen, which is a key inducer of angiogenesis, both during embryogenesis and in adult processes such as wound healing and organ angiogenesis. ${ }^{22}$ VEGF has a critical role in renal development by promoting endothelial cell differentiation, capillary formation and tubular epithelial cell proliferation. ${ }^{24}$ VEGF produced by differentiating nephrons is a chemoattractant for exogenous endothelial cells that direct their migration toward developing nephrons in vitro. ${ }^{25}$ Thus, Salll induces angiogenesis by stimulation of VEGF-A promoter activity. It is possible that the angiogenic properties of Salll are also involved in nephrogenesis.

\section{CONFLICT OF INTEREST}

The authors declare no conflict of interest.

\section{ACKNOWLEDGEMENTS}

This work was supported by financial grants from the Ministry of Education, Science, Sports, and Culture of Japan (20590707 and S0801033) and by a Nihon University Multidisciplinary Research Grant (08-017, 08-020, 09-011, 09-012).

1 Folkman J. Angiogenesis in cancer, vascular, rheumatoid and other disease. Nat Med 1995; 1: 27-31.

2 Risau W. Mechanisms of angiogenesis. Nature 1997; 386: 671-674.

3 Ikeda Y, Fukuda N, Wada M, Matsumoto T, Satomi A, Yokoyama S, Saito S, Matsumoto $\mathrm{K}$, Kanmatsuse $\mathrm{K}$, Mugishima $\mathrm{H}$. Development of angiogenic cell and gene therapy by transplantation of umbilical cord blood with vascular endothelial growth factor gene. Hypertens Res 2004; 27: 119-128.

4 Yancopoulos GD, Davis S, Gale NW, Rudge JS, Wiegand SJ, Holash J. Vascular-specific growth factors and blood vessel formation. Nature 2000; 407: 242-248.

5 Maisonpierre PC, Suri C, Jones PF, Bartunkova S, Wiegand SJ, Radziejewski C, Compton D, McClain J, Aldrich TH, Papadopoulos N, Daly TJ, Davis S, Sato TN, Yancopoulos GD. Angiopoietin-2, a natural antagonist for Tie2 that disrupts in vivo angiogenesis. Science 1997; 277: 55-60.

6 Hellstrom M, Kalen M, Lindahl P, Abramsson A, Betsholtz C. Role of PDGF-B and PDGFR-beta in recruitment of vascular smooth muscle cells and pericytes during embryonic blood vessel formation in the mouse. Development 1999; 126: 3047-3055.

7 Holash J, Wiegand SJ, Yancopoulos GD. New model of tumor angiogenesis: dynamic balance between vessel regression and growth mediated by angiopoietins and VEGF. Oncogene 1999; 18: 5356-5362.
8 Buck A, Kispert A, Kohlhase J. Embryonic expression of the murine homologue of SALL1, the gene mutated in Townes-Brocks syndrome. Mech Dev 2001; 104: 143-146.

9 Kiefer SM, Ohlemiller KK, Yang J, McDill BW, Kohlhase J, Rauchman M. Expression of a truncated Sall1 transcriptional repressor is responsible for Townes-Brocks syndrome birth defects. Hum Mol Genet 2003; 12: 2221-2227.

10 Kohlhase J, Wischermann A, Reichenbach H, Froster U, Engel W. Mutations in the SALL1 putative transcription factor gene cause Townes-Brocks syndrome. Nat Genet 1998; 18: 81-83.

11 Rebar EJ, Huang Y, Hickey R, Nath AK, Meoli D, Nath S, Chen B, Xu L, Liang Y, Jamieson AC, Zhang L, Spratt SK, Case CC, Wolffe A, Giordano FJ. Induction of angiogenesis in a mouse model using engineered transcription factors. Nat Med 2002; 8: 1427-1432.

12 Dai Q, Huang J, Klitzman B, Dong C, Goldschmidt-Clermont PJ, March KL, Rokovich J, Johnstone B, Rebar EJ, Spratt SK, Case CC, Kontos CD, Annex BH. Engineered zinc finger-activating vascular endothelial growth factor transcription factor plasmid DNA induces therapeutic angiogenesis in rabbits with hind-limb ischemia. Circulation 2004; 110: 2467-2475.

13 Liu PQ, Rebar EJ, Zhang L, Liu Q, Jamieson AC, Liang Y, Qi H, Li PX, Chen B, Mendel MC, Zhong X, Lee YL, Eisenberg SP, Spratt SK, Case CC, Wolffe AP. Regulation of an endogenous locus using a panel of designed zinc finger proteins targeted to accessible chromatin regions. Activation of vascular endothelial growth factor A. J Biol Chem 2001; 276: 11323-11334.

14 Matsumoto T, Bohman S, Dixelius J, Berge T, Dimberg A, Magnusson P, Wang L, Wikner C, Qi JH, Wernstedt C, Wu J, Bruheim S, Mugishima H, Mukhopadhyay D, Spurkland A, Claesson-Welsh L. VEGF receptor-2 Y951 signaling and a role for the adapter molecule TSAd in tumor angiogenesis. EMBO J 2005; 24: 2342-2353.

15 Beerli RR, Barbas CF. Engineering polydactyl zinc-finger transcription factors. Nat Biotechnol 2002; 20: 135-141.

16 Pages G, Pouyssegur J. Transcriptional regulation of the vascular endothelial growth factor gene-A concert of activating factors. Cardiovasc Res 2005; 65: 564-573.

17 Akiri G, Nahari D, Finkelstein Y, Le SY, Elroy-Stein O, Levi BZ. Regulation of vascular endothelial growth factor (VEGF) expression is mediated by internal initiation of translation and alternative initiation of transcription. Oncogene 1998; 17: 227-236.

18 Nishinakamura R, Matsumoto Y, Nakao K, Nakamura K, Sato A, Copeland NG, Gilbert DJ, Jenkins NA, Scully S, Lacey DL, Katsuki M, Asashima M, Yokota T. Murine homolog of SALL1 is essential for ureteric bud invasion in kidney development. Development 2001; 128: 3105-3115.

19 Netzer C, Rieger L, Brero A, Zhang CD, Hinzke M, Kohlhase J, Bohlander SK. SALL1, the gene mutated in Townes-Brocks syndrome, encodes a transcriptional repressor which interacts with TRF1/PIN2 and localizes to pericentromeric heterochromatin. Hum Mol Genet 2001; 10: 3017-3024.

20 Netzer C, Bohlander SK, Hinzke M, Chen Y, Kohlhase J. Defining the heterochromatin localization and repression domains of SALL1. Biochim Biophys Acta 2006; 1762: 386-391.

21 Yamashita K, Sato A, Asashima M, Wang PC, Nishinakamura R. Mouse homolog of SALL1, a causative gene for Townes-Brocks syndrome, binds to A/T-rich sequences in pericentric heterochromatin via its C-terminal zinc finger domains. Genes Cells 2007; 12: 171-182.

22 Carmeliet P, Ferreira V, Breier G, Pollefeyt S, Kieckens L, Gertsenstein M, Fahrig M, Vandenhoeck A, Harpal K, Eberhardt C, Declercq C, Pawling J, Moons L, Collen D, Risau W, Nagy A. Abnormal blood vessel development and lethality in embryos lacking a single VEGF allele. Nature 1996; 380: 435-439.

23 Ferrara N, Carver-Moore K, Chen H, Dowd M, Lu L, O'Shea KS, Powell-Braxton L, Hillan $\mathrm{KJ}$, Moore MW. Heterozygous embryonic lethality induced by targeted inactivation of the VEGF gene. Nature 1996; 380: 439-442.

24 Robert B, St John PL, Hyink DP, Abrahamson DR. Evidence that embryonic kidney cells expressing flk-1 are intrinsic, vasculogenic angioblasts. Am J Physiol 1996; 271: F744-F753.

25 Tufro A. VEGF spatially directs angiogenesis during metanephric development in vitro. Dev Biol 2000; 227: 558-566. 